\title{
Intraductal Carcinoma of the Minor Salivary Gland
}

National Cancer Institute

\section{Source}

National Cancer Institute. Intraductal Carcinoma of the Minor Salivary Gland. NCI

Thesaurus. Code C62192.

A rare, low-grade adenocarcinoma that arises from the salivary glands. It is characterized by the presence of cystic structures lined by ductal cells which are arranged in cribriform patterns. Adjacent ducts show intraductal proliferation. 